\title{
State Markers of Depression in Sleep EEG: Dependency on Drug and Gender in Patients Treated with Tianeptine or Paroxetine
}

\author{
H Murck',2, T Nickel', H Künzel', IA Antonijevic', J Schill', A Zobel', A Steiger*,', A Sonntag' and \\ F Holsboer' \\ 'Max Planck Institute of Psychiatry, Munich, Germany; ${ }^{2}$ Laxdale Ltd., Stirling, UK
}

\begin{abstract}
Tianeptine enhances while paroxetine inhibits serotonin reuptake into neurons; however, both show an antidepressive action. A subgroup of 38 depressed patients from a drug trial comparing the efficacy of tianeptine with that of paroxetine was studied with regard to their effects on sleep regulation, especially in relation to treatment response. We recorded sleep EEGs at day 7 and day 42 after the start of treatment with either compound, which allows measurement of changes due to the antidepressive medication in relation to the duration of treatment. Spectral analysis of the non-REM sleep EEG revealed a strong decline in the higher sigma frequency range (I 4 $16 \mathrm{~Hz})$ in male treatment responders independent of medication, whereas nonresponders did not show marked changes in this frequency range independent of gender. The patients receiving paroxetine showed less REM sleep and more intermittent wakefulness compared to the patients receiving tianeptine. REM density after I week of treatment was a predictor of treatment response in the whole sample. Psychopathological features with regard to the score in single items of the HAMD revealed predictive markers for response, some of which were opposite in the gender groups, especially those related to somatic anxiety. Changes in REM density were inversely correlated to the changes in HAMD in the paroxetine, but not the tianeptine, group. Our data suggest the importance of taking gender into account in the study of the biological effects of drugs. The study further points to the importance of the higher sigma frequency range in the sleep EEG of non-REM sleep and REM density as a marker of treatment response.

Neuropsychopharmacology (2003) 28, 348-358. doi: I0. I 038/sj.npp. 1300029
\end{abstract}

\section{INTRODUCTION}

Most studies that investigated the effect of antidepressants upon sleep agreed that tricyclic antidepressants and selective serotonin reuptake inhibitors (SSRIs) suppress rapid eye movement (REM) sleep (Sharpley and Cowen, 1995). Some antidepressive substances lack a suppressive effect on REM sleep, like trimipramine (Steiger et al, 1989) nefazodone (Vogel et al, 1998) and bupropione (Nofzinger et al, 1995). However, other studies show that early changes of REM sleep parameters, especially REM latency and percentage amount of REM during the sleep period time, might predict treatment outcome with substances, which have an accute effect on REM sleep like amitriptyline (Kupfer et al, 1981; Gillin et al, 1978) and clomipramine (Höchli et al, 1986). Furthermore, changes in REM sleep, especially REM density, occur in the course of antidepressive treatment with fluoxetine (Buysse et al, 1999a) leading to an increase in REM density, whereas under nonpharma-

\footnotetext{
*Correspondence: Dr A Steiger, Max Planck Institute of Psychiatry, Kraepelinstrasse 10, D-80804 Munich, Germany, Tel: +49 8930622236, Fax: +49 8930622 548, E-mail: steiger@mpipsykl.mpg.de Received 19 December 200 I; revised 17 June 2002; accepted 20 June 2002
}

cological treatment (Thase et al, 1994; Buysse et al, 1999a) REM density decreases. In drug-free depressed patients, an increased REM density is a state marker of depression (Lauer et al, 1991).

Concerning changes in non-REM sleep the actions of antidepressants are inconsistent. For example, some increase slow-wave sleep (SWS) as tricyclic antidepressants like amitriptyline and trimipramine, others decrease it, as SSRIs like fluoxetine and paroxetine (Sharpley and Cowen, 1995). Besides these differences related to different drugs, gender also has to be taken into account for the interpretation of sleep-EEG characteristics. Gender differences exist in the sleep EEG of depressed patients under baseline conditions as a higher incidence of EEG delta activity (Reynolds et al, 1990), more delta and beta EEG activity of a higher amplitude, especially in the right hemisphere (Armitage et al, 1995a) or power of the deltaand sigma-frequency range in females (Antonijevic et al, 2000a). A challenge with growth-hormone-releasing hormone (GHRH) led to an increase in sleep efficiency and stage 2 sleep in males, but a decrease in female healthy and depressed subjects (Antonijevic et al, 2000a). Recently a differential efficacy for SSRIs compared to tricyclics in men compared to women has been described (Kornstein et al, 2000). With respect to the possible interactions between the 
type of drug and gender, we performed a study on the effect of two drugs with opposite actions on serotoninergic neurotransmission, that is, paroxetine as an SSRI and tianeptine as a serotonin reuptake enhancer (Mocaer et al, 1988). This property might correlate with the opposing action of tianeptine and the SSRI fluoxetine on hippocampal electrical activity (Shakesby et al, 2002). Furthermore, tianeptine decreases stress-induced HPA-axis activity in a similar way as desipramine, but different from paroxetine (Delbende et al, 1994; Connor et al, 2000). Despite this diverging effect of the tianeptine and SSRIs, they have some properties in common as tianeptine and the SSRI sertraline showed similar effects in the Behavioral Despair Test and in antagonizing the behavioral effect of olfactory bulbectomy (Kelly and Leonard, 1994). At the cellular level, the effect of tianeptine was similar to the tricyclic antidepressants imipramine, amitriptyline and desipramine and to the SSRI fluoxetine in inhibiting glucocorticoid-mediated gene transcription (Budziszewska et al, 2000).

We performed the study in a subgroup of patients taking part in a study comparing clinical and endocrine parameters in patients with depression (Nickel et al, in press). The subjects from this study were examined in the sleep laboratory for assessment of the changes in the sleep EEG in the course of the treatment. The aim was to define common changes in the sleep EEG of depressed patients in the course of treatment despite different modes of action of the antidepressant drugs, that is, to investigate which changes in the sleep EEG might be correlated with a treatment response independent of the type of medication.

\section{MATERIALS AND METHODS}

In a double-blind protocol, we compared the effect of tianeptine $v s$ paroxetine in 44 patients with an episode of major depression. This study was approved by the Ethics Committee for Human Experiments of the Bavarian Medical Council (Bayerische Ärztekammer). The patients were hospitalized for evaluation and treatment of depression. At initial evaluation, all had to meet the criteria for a major depressive episode or bipolar I or II disorder (depressed) according to DSM-IV (American Psychiatric Association, 1994) with a Hamilton depression (HAMD) score on the 21item HAMD scale $>18$. To exclude spontaneous remission, the difference of the total HAMD score between selection and inclusion at day 1 (D1) had to be $<6$ points. Previous secondary and comorbid diagnoses were ruled out in an examination conducted by a senior psychiatrist. Other exclusion criteria were pregnancy or lack of effective contraception in women of child-bearing potential, a serious risk of suicide, a history of drug or alcohol abuse or dependence, and severe diseases like uncontrolled cardiovascular, neurologic or metabolic disorders. Concurrent medical conditions that required pharmacological treatment just before or during the study, which might influence the pharmacokinetics of the applied drugs or the endocrinological investigations (combined Dex-CRH test), were also considered to be the criteria for exclusion. During the study, no other psychotropic drug treatment was allowed except for chloral hydrate in a dose of up to $2 \mathrm{~g} /$ day on an as-required basis. The prescription of somatic treatment without interference with depression was allowed. The patients were not treated with depot neuroleptics, fluoxetine and irreversible monoanime-oxidase inhibitors for at least 8 weeks prior to admission, and patients were drug-free for a minimum of 1 week prior to the study.

Patients received either $20 \mathrm{mg}$ paroxetine or $37.5 \mathrm{mg}$ tianeptine beginning at D1. At day 21 (D21), the same dose or double the dose, depending on treatment response, was administered until day 42 (D42). After D7 and at D42, an investigation of the sleep EEG was done. The assessment of psychopathology was done on D1, D7, D14, D21, D28, D35 and D42; we give here only the data of the 38 patients included in the sleep-EEG analysis at baseline (D1) and the days of the sleep-EEG examinations (D7 and D42).

After a night of accommodation, the subjects underwent a polysomnographic examination. The subjects were allowed to sleep between 23:00 and 7:00 h, which was also the time, when the light was turned off and the sleep recordings were made. The recordings consisted of two EEGs (C3-A2, C4-A1; time constant $0.3 \mathrm{~s}$, low-pass filtering $70 \mathrm{~Hz}$ ), vertical and horizontal electro-oculograms (EOG), an electromyogram (EMG) and an electrocardiogram (ECG). The EEG signals were filtered (EEG: high-pass $0.53 \mathrm{~Hz},-3 \mathrm{~dB}$; low-pass $70 \mathrm{~Hz},-3 \mathrm{~dB} ;-12 \mathrm{~dB}$ octave, band-stop between 42 and $62 \mathrm{~Hz},-3 \mathrm{~dB}$ ) and transmitted by an optical fiber system to the polygraph (Schwartzer, ED 24). By means of a personal computer, EEG signals were additionally sampled by an 8-bit analog-to-digital converter at a sampling rate of $100 \mathrm{~Hz}$ and stored on disk for further spectral analysis. Sleep EEGs were rated visually according to standard criteria (Rechtschaffen and Kales, 1968) by an experienced rater who was blind to the study protocol. The parameters used were: SOL - sleep onset latency (sleep onset defined as the first epoch of $30 \mathrm{~s}$ containing stages 2, 3, 4 or REM sleep) ( $\mathrm{min}$ ); time spent in each of the following sleep stages during time in bed: non-REM stage 2, SWS - slow-wave sleep (non-REM stages 3 and 4), REM; REM latency (interval from onset until the first epoch containing stage REM) (min); REM density $\left(\mathrm{min}^{-1}\right.$ ) (the average ratio of 3-s mini-epochs of REM sleep including REMs to the total number of 3-s mini-epochs of REM sleep per minute); and the duration of intermittent wakefulness (IW) (min). Spectral analysis was initially performed on the distinct frequency ranges delta $(0.8-4.5 \mathrm{~Hz})$, theta $(4.5-8.0 \mathrm{~Hz})$, alpha $(8.0-11.8 \mathrm{~Hz})$, sigma $(11.8-15.2 \mathrm{~Hz})$ and beta $(15.2-19.0 \mathrm{~Hz})$ and thereafter additionally in three smaller ranges covering the sigma frequency band.

The evolution in HAMD and the sleep-EEG variables between D7 and D42 were assessed for significance with analysis of covariance (ANCOVA) for repeated measures with time under treatment ('time', ie value at D7 compared to value at D42) as the within-subjects factor defining treatment response. Furthermore 'gender' and 'drug' were used as between-subjects factors, and finally 'age' as the covariate to control for age effects. We computed 'global effects' using multivariate analysis of covariance (MANCOVA) (1) for selected parameters after conventional sleep analysis and (2) for the five spectral ranges delta to beta. Additionally, the univariate statistics is shown to clarify which variables led to the differences. To test for changes in the higher alpha and sigma frequency range, we performed an additional analysis for three spectral ranges 10-12, 12-14 
and $14-16 \mathrm{~Hz}$, which behave differentially and therefore have to be separated (Antonijevic et al, 2000a). To test further if there is a specific pattern of psychopathological characteristics that differentiates responders from non responders, an analysis of variance was performed at the single HAMD items using response (resp) (ie HAMD $\leqslant 10$ at $\mathrm{D} 42)$, gender and drug as factors and age as covariate.

A level of significance of $p<0.05$ was considered significant. The cutoff for presenting the $p$-value when not significant was $p \leqslant 0.1$. The data are presented as mean \pm SD.

\section{RESULTS}

\section{Demographic Data}

A total of 38 subjects from the study took part in two sleep examinations, one at D7 of treatment, the other at D42. Of the subjects, 21 received tianeptine as medication and 17 paroxetine. The age distribution by gender and type of medication was: paroxetine, male $(n=9): 50.0 \pm 9.8$ years; paroxetine, female $(n=8): 50.8 \pm 15.2$ years; tianeptine, male $(n=8): 40.9 \pm 10.8$ years; tianeptine, female $(n=13)$ : $49.5 \pm 11.8$ years. Analysis of variance using gender and type of medication as factors did not reveal any interaction with respect to age. All patients were classified as unipolar disorder.

\section{Treatment Response (Effect of time)}

For the evolution of the HAMD values between D7 and D42, we found a highly significant effect of time (treatment effect; $p<0.001$ ) without an effect of gender and drug and qualitatively no effect of age which was used as a covariate on treatment outcome $(\mathrm{F}=0.72, p=0.79)$. A trend for a gender $\times$ drug interaction was revealed $(\mathrm{F}=4.0, p=0.054)$, which means that the effect of the two treatments tends to depend on gender. For male subjects, no drug $\times$ time interaction was revealed $(\mathrm{F}=0.04, p=0.84)$, whereas a significant $d r u g \times$ time interaction existed for females $(\mathrm{F}=8.3, p=0.01)$. Table 1 shows the HAMD values for the subgroups.

\section{Effects on Conventional Sleep-EEG Parameters}

For the analysis of sleep variables, we chose REM density, REM sleep duration (REM), slow-wave sleep duration (SWS), duration of stage 2 (S2), IW and REM latency. We corrected for age using it as a covariate within the MANOVA. We qualitatively could not find a global effect of age for the variables chosen ( $\mathrm{df} 1,33 ; \mathrm{F}=1.0, p=0.47)$.
In the whole group, using the multivatiate analysis we found no global effect of time $(\mathrm{F}=1.9, \quad p=0.113)$. Univariate analysis however showed a significant decrease in IW $(\mathrm{F}=7.9, p<0.01)$ in the course of treatment.

A significant drug $(\mathrm{F}=16.7, p<0.001)$ effect occurred with a markedly lower REM density and less REM sleep and more IW with paroxetine compared to tianeptine (Table 2). Furthermore, a drug $\times$ time $(\mathrm{F}=3.0, p<0.05)$ interaction was revealed, mainly due to REM sleep parameters (Table 2), but no global interaction involving gender. Only a trend for a difference between male and female subjects existed for the selected variables $(\mathrm{F}=2.2, p<0.08)$, but univariate analysis revealed a significantly higher amount of SWS $(\mathrm{F}=5.0, p<0.05)$ and a prolonged REM latency $(\mathrm{F}=7.8$, $p<0.01)$ in females compared to males. No time $\times$ gender $(\mathrm{F}=0.88, p=0.53)$ and no time $\times$ gender $\times \operatorname{drug}(\mathrm{F}=0.20$, $p=0.97)$ interactions occurred in the global analysis and also not in any single variable.

As a result of the absence of a significant gender and gender $\times$ time interaction, we split the groups with respect to drug regardless of gender for the further analysis. For paroxetine, we found a trend to a time effect $(p<0.1)$, with a significant change in REM density, REM sleep duration and the amount of waking (Table 2). Tianeptine had no effect on any of the variables analyzed in the course of treatment.

Dependency of sleep changes with regard to treatment response. To further establish if sleep parameters distinguish responders and nonresponders we performed a MANOVA using response as a factor (cutoff: HAMD $\leqslant 10$ at D42). The data for the responder and nonresponder groups are additionally shown in Table 2 . There was no global effect in any of the analyses containing response as a factor, but a significant univariate effect of response on REM density was seen $(\mathrm{F}=1.1, p<0.05)$, that is, REM density distinguishes the responders from the nonresponders. Correlating changes in sleep with changes in HAMD in the course of treatment ('time'), we found a significant inverse correlation between the relative increase in REM density and the relative decrease in Hamilton depression score $(\mathrm{F}=5.7, p<0.05)$ for the paroxetine group, whereas this effect could not be shown in the tianeptine group (Figure 1).

\section{Effects on Spectral Analysis}

We performed a MANOVA on the means of the spectral power ranges delta, theta, alpha, sigma and beta using age as a covariate. As a qualitative finding, the analysis revealed a significant dependency of these variables on age ( $\mathrm{df} 1,23$; $\mathrm{F}=8.4, p<0.001)$ due to a decline in the delta $(\mathrm{F}=16.2$,

Table I HAMD Scores for the Patients Divided with Regard to Gender and Medication

\begin{tabular}{llllll}
\hline & \multicolumn{2}{l}{ Tianeptine $(\boldsymbol{n}=\mathbf{2 1})$} & & \multicolumn{2}{l}{ Paroxetine $(\boldsymbol{n}=\mathbf{1 7})$} \\
\cline { 2 - 3 } & Male $(\mathbf{n}=\mathbf{8})$ & Female $(\boldsymbol{n}=\mathbf{1 3})$ & & Male $(\boldsymbol{n}=\mathbf{9})$ & Female $(\boldsymbol{n}=\mathbf{8})$ \\
\hline DI & $28.6 \pm 5.9$ & $27.2 \pm 3.7$ & & $28.6 \pm 4.5$ & $29.8 \pm 3.0$ \\
D7 & $23.4 \pm 9.3$ & $23.1 \pm 5.1$ & & $25.3 \pm 4.1$ & $25.8 \pm 5.0$ \\
D42 & $13.3 \pm 8.5$ & $17.4 \pm 8.0$ & & $16.1 \pm 10.3$ & $9.4 \pm 6.6$ \\
\hline
\end{tabular}


Table 2 Effects on Conventional Sleep-EEG Parameters Separated for the Drugs

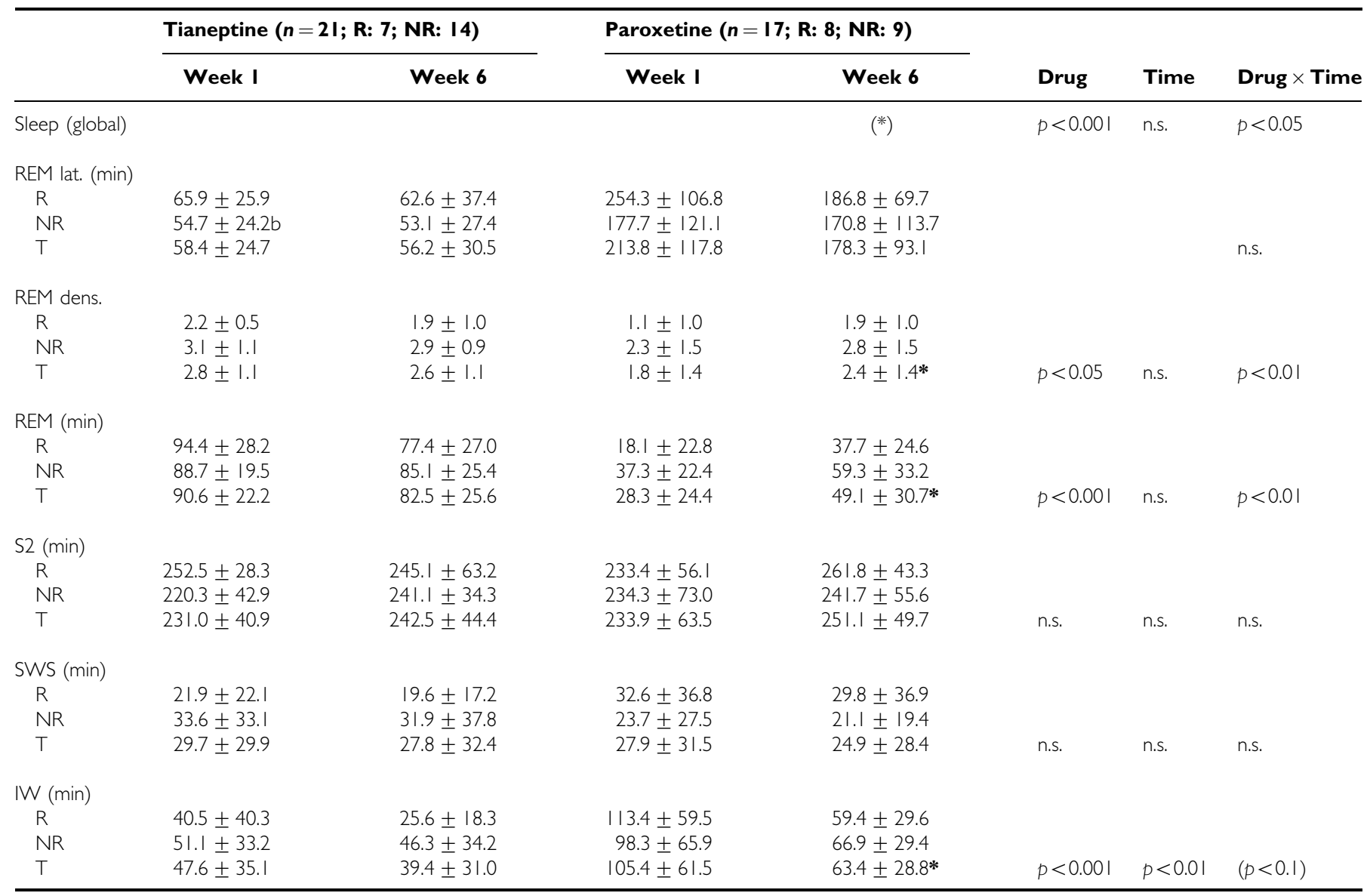

Drug, time and drug $\times$ time interaction given for total group $(T)$. Additionally the values for responders $(R)$ and nonresponders (NR) are shown. Significant effects within the drug groups for $T$ are given as $*$ for $p<0.05$ or (*) for $p<0.1$ ).

$p<0.001)$, alpha $(\mathrm{F}=6.6, p<0.05)$ and sigma frequency range $(\mathrm{F}=14.8, p<0.001)$. This age-related change in sigma power was only due to a decline in the $10-12 \mathrm{~Hz}(R=-0.41$, $p<0.05)$ and $12-14 \mathrm{~Hz}(R=-0.48, p<0.01)$ band, but not in the $14-16 \mathrm{~Hz}$ band $(R=-0.14$, n.s.).

Using multivariate analysis, a highly significant effect of gender was revealed with a general increase over the whole spectrum $(\mathrm{F}=4.9, \quad p<0.01)$. There was however no influence of gender on the effect of time (gender $\times$ time interaction).

A significant effect of drug $(\mathrm{F}=5.4, p<0.01)$ due to differences in the sigma and theta range could be observed, revealing a significant different action of both drugs on the sleep EEG of non-REM sleep, but no drug $\times$ time interaction occurred.

Multivariate analysis revealed a significant effect of time $(\mathrm{F}=5.93, p<0.01)$, which is mainly due to a decrease of the EEG power in the sigma frequency range $(\mathrm{F}=11.3$, $p<0.01)$. This effect is due to a change of the higher frequency $(14-16 \mathrm{~Hz})$ spindles $(\mathrm{F}=8.6, p<0.01)$, whereas the changes in the lower frequency bands $10-12$ and 12$14 \mathrm{~Hz}$ were not significant.

Dependency of the sleep changes with regard to treatment response. The group of responders and nonresponders in the whole group, using multivariate analysis, did not differ in EEG spectral parameter or with regard to the effect of time. However, a significant gender $\times$ response interaction on the effect of time (treatment effect) existed $(\mathrm{F}=5.2, p<0.01)$ due to changes in alpha and sigma power. We therefore split the group according to gender regardless of drug, which had no influence on the spectral changes in time despite the reported significant interaction of the spectral data with drug. The data are presented in Table $3 \mathrm{a}$ and $\mathrm{b}$. To justify this procedure, we additionally tested the following results post hoc in the drug groups separately and found by trend the same effects (data not shown). Male patients showed a significant effect in time, which differed in responders and nonresponders: responders showed a significant decrease in the alpha and sigma frequency range, whereas nonresponders showed an increase in the alpha range (Table 3a). Females presented variable changes with respect to treatment response.

Correlating the spectral changes with those of the single items of the HAMD, we found for the whole group a significant correlation between the change in delta power on the one side with the changes of the score of item 6 (early awakening) (correlation according to Pearson's $R= \pm 0.48$, $p<0.01)$, item 10 (psychic anxiety) $(R= \pm 0.38, p<0.05)$ and item 12 (decreased appetite) $(R= \pm 0.38, p<0.05)$, meaning that a decrease in delta power is associated with a 

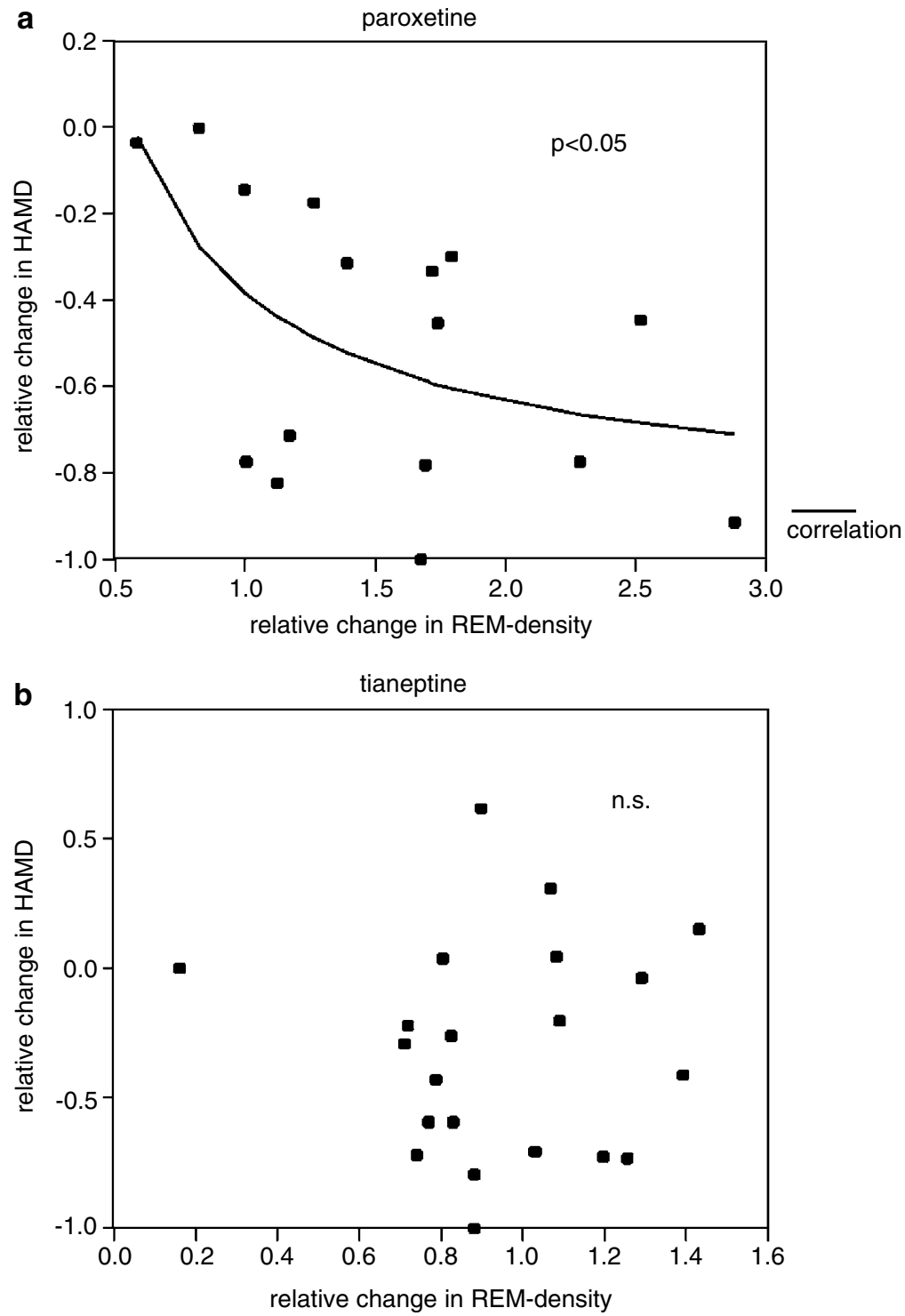

Figure I Correlation between the relative change in HAMD (difference HAMD at D7 - HAMD at D42) in the course of treatment in relation to the relative change in REM density. (a) with paroxetine, REM density increases with the decline in HAMD; (b) with tianeptine, no systematic change could be observed.

better normalization of early awakening, of anxiety and of decreased appetite. As both effects were variable in the total group, no statisticaly significant change of the means occurred. The change in sigma power was positively correlated with the change in the score of item 15 (hypochondriasis, better: relatedness to bodily complaints). After splitting the group according to genders for male subjects the correlation between the changes in item 6 and delta power was conserved $(R=0.68, p<0.05)$, whereas for females a correlation of the changes between item 12 and delta power $(R= \pm 5.5, p<0.05)$ and item 15 and sigma power $(R=-0.48, p<0.05)$ were still present. In females, however, the correlation of the change of item 15 and sigma power is reversed to the total group. This shows that the general trend for the females with respect to the change in somatic complaints with sigma power, that is, that an increase in sigma power is correlated with a decrease in somatic complaints, differs from that of males and is similar to the general pattern of response to nonresponse with regard to gender (see Figure 3).

Differentiating the higher alpha and sigma band in the spectral ranges $10-12,12-14$ and $14-16 \mathrm{~Hz}$, an effect of time (treatment effect) was revealed for the total group $(\mathrm{F}(1,28)=4.5, p<0.05)$ due to the $14-16 \mathrm{~Hz}$ range $(\mathrm{F}=6.6, p<0.05)$. A strong sex $\times$ response $\times$ time interaction $(\mathrm{F}=7.2, p<0.001)$ existed due to changes in the $10-12 \mathrm{~Hz} \quad(\mathrm{~F}=6.4, \quad p<0.05) \quad$ and $\quad 14-16 \mathrm{~Hz} \quad(\mathrm{~F}=14.8$, $p<0.001)$ range. Splitting again into the gender groups shows that a variable and therefore nonsignificant effect on spectral analysis parameters occurred in females, but a significant time effect occurred in males $(\mathrm{F}=4.8$, $p<0.05)$ as a result of a change in the $14-16 \mathrm{~Hz}$ range $(\mathrm{F}=16.4, p<0.01)$. Furthermore, in males, a significant response $\times$ time interaction $(\mathrm{F}=7.2, p<0.01)$ due to the $14-16 \mathrm{~Hz}$ range $(\mathrm{F}=16.5, p<0.005)$ was revealed (Figure 2) similar to the changes in the whole sigma 
Table 3 Spectral Changes in Nonresponders vs Responders

\begin{tabular}{|c|c|c|c|c|c|c|c|}
\hline \multirow[t]{2}{*}{ (a) Male } & \multicolumn{2}{|c|}{ Nonresponder $(n=7)$} & \multicolumn{2}{|c|}{ Responder $(n=6)$} & \multirow[b]{2}{*}{ Resp/nonresp } & \multirow[b]{2}{*}{ Time } & \multirow[b]{2}{*}{ Resp $\times$ time } \\
\hline & Week I & Week 6 & Week I & Week 6 & & & \\
\hline delta & $115.9 \pm 33.7$ & $|22| \pm 35.2$. & $136.2 \pm 38.3$ & $162.7 \pm 78.6$ & n.s. & n.s. & n.s. \\
\hline theta & $15.1 \pm 4.7$ & $15.5 \pm 4.7$ & $24.1 \pm 11.5$ & $24.7 \pm 16.0$ & n.s. $(p<0.1)$ & n.s. & n.s. \\
\hline alpha & $10.4 \pm 4.8$ & $12.2 \pm 6.2 *$ & $23.5 \pm 15.9$ & $19.0 \pm 14.1$ **** & n.s. $(p<0.1)$ & n.s. $(p<0.1)$ & $p<0.001$ \\
\hline
\end{tabular}

(b) Female

\begin{tabular}{|c|c|c|c|c|c|c|c|}
\hline & \multicolumn{2}{|c|}{ Nonresponder $(n=12)$} & \multicolumn{2}{|c|}{ Responder $(n=7)$} & \multirow[b]{2}{*}{ Resp/nonresp } & \multirow[b]{2}{*}{ Time } & \multirow[b]{2}{*}{ Resp $\times$ time } \\
\hline & Week I & Week 6 & Week I & Week 6 & & & \\
\hline Global & & & & & n.s. & $p<0.05$ & n.s. \\
\hline theta & $31.9 \pm 12.9$ & $31.8 \pm 14.6$ & $30.9 \pm 7.8$ & $29.3 \pm 4.9$ & n.s. & n.s. & n.s. \\
\hline alpha & $22.0 \pm 9.0$ & $20.4 \pm 7.0$ & $24.9 \pm 10.2$ & $25.1 \pm 6.5$ & n.s. & n.s. & n.s. \\
\hline sigma & $11.7 \pm 4.8$ & $10.6 \pm 4.3^{*}$ & $14.2 \pm 7.6$ & $13.9 \pm 5.6$ & n.s. & n.s. & n.s. \\
\hline beta & $5.5 \pm 2.0$ & $5.3 \pm 2.1$ & $6.3 \pm 2.6$ & $6.8 \pm 3.2$ & n.s. & n.s. & n.s. \\
\hline
\end{tabular}

*Significance levels for the single groups.

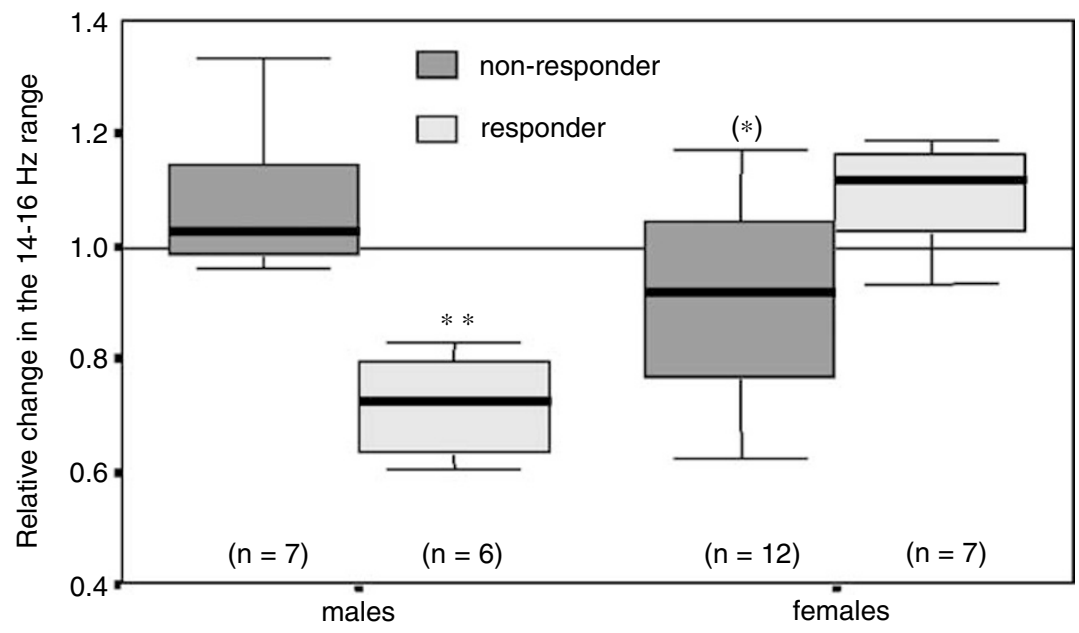

Figure 2 Relative change of EEG power in the $14-16 \mathrm{~Hz}$ range divided into gender comparing responders and nonresponders. Male and female subjects behave differentially concerning treatment response (for details, see text).

frequency range (s.o.). This specifies the $14-16 \mathrm{~Hz}$ range as being responsible for the response $\times$ time interaction. The independence of this effect from the kind of medication has to be particularly stressed.

\section{Outcome Prediction}

In the next step, we correlated the HAMD scores at D42 with sleep parameters of D7 in order to find out predictive sleep parameters for the clinical outcome. We found that the REM density after the first week of treatment is a strong marker for the outcome in the paroxetine-treated patients, whereas this correlation did not exist in tianeptine-treated patients (Figure 3).

Focusing on psychopathological patterns that might be related to the sleep-EEG pattern, we used the single items of the HAMD to perform a univariate analysis for every single item using drug, gender, and response as factors and age as a covariate. For none of the single variables was an interaction with drug observed. We found that high values of item 10 (psychic anxiety) and item 12 (somatic symptoms gastrointesinal, ie decreased appetite) are significantly related to nonresponse $(p<0.05)$, independent of gender. For item 2 (feelings of guilt), item 9 (agitation), item 11 (somatic anxiety) and item 15 (hypochondriasis), a significant gender $\times$ response interaction was revealed, showing that males with high somatic complaints (items 11 and 15) respond worse $(p<0.05$ for either item), whereas women with high somatic complaints respond better to treatment. High scores on feelings of guilt and agitation (items 2 and 9), on the other hand, predict nonresponse in males (item 2: $p<0.05$; item 9: $p<0.1$ ), but had no significant influence in females. 


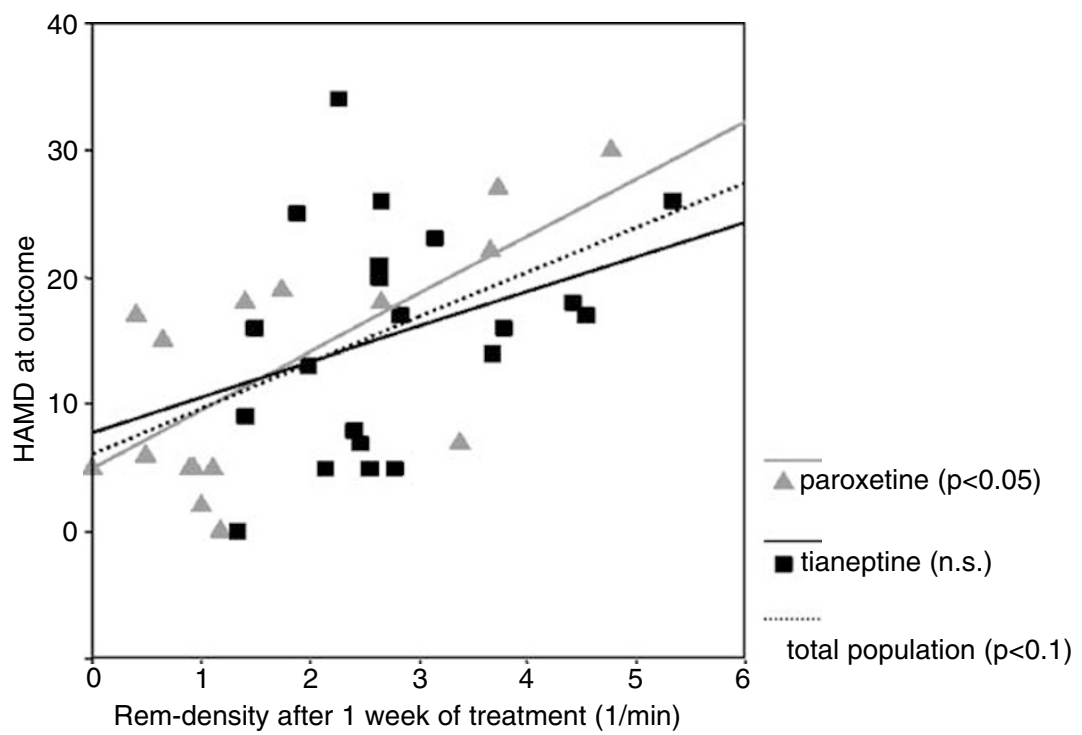

Figure 3 HAMD at D42 in relation to the REM density at D7. With paroxetine, the REM density at D7 is correlated to treatment outcome, whereas with tianeptine no significant correlation existed.

\section{DISCUSSION}

The main findings of our study comparing the relation of sleep changes with two different antidepressant substances were firstly the finding that the power in the higher sigma frequency range of non-REM $(14-16 \mathrm{~Hz})$ decreased significantly only in male responders to treatment, but not male nonresponders and female patients, which was true regardless of medication. During the course of treatment, REM sleep duration and REM density increased in the paroxetine group (starting from a lower level), whereas in the tianeptine group REM density was not affected. REM density after 1 week of treatment predicted treatment outcome in the paroxetine group regardless of medication. A trend to a gender difference also existed in the efficacy of tianeptine and paroxetine. Qualitatively, responders and nonresponders to treatment can be separated by their symptom pattern. This differentiation was partially dependent on gender, but independent of the type of medication.

The changes in HAMD reported in this subgroup of patient from a bigger study are in agreement with the changes in the total sample (Nickel et al, in press). Gender differences in the efficacy of serotoninergic acting drugs have recently been found for the treatment of obsessive compulsive disorder, with women responding better to clomipramine and fluoxetine compared to men (Mundo et $a l$, 1999). Similarly, women treated for depression respond less well to tricyclic antidepressants and better to SSRIs and MAO inhibitors (Kornstein, 1997; Kornstein et al, 2000). These reports are in line with the data presented here.

The interpretations of the sleep-EEG findings are hampered by the fact that no pretreatment values exist for the sample. We chose a design focusing on the changes in the course of the treatment as a possible correlate of the adaptive changes, which seem to be more relevant as acute actions of antidepressants, since the latter can be very diverse (see the Introduction). For tianeptine, no human data on its acute effects are published. We can report here preliminary data of six patients from the present study (four male, two female; two responders, four nonresponders). In this sample the only significant changes were a decrease in REM density $(2.5 \pm 0.7$ after placebo $v s 1.6 \pm 0.7$ after tianeptine; $p<0.05)$ and in IW $(70.3 \pm 45.7 \mathrm{~min} \quad v s$ $61.4 \pm 41.5 \mathrm{~min} ; \quad p<0.05)$. SWS increased by trend $(18.8 \pm 13.0 \mathrm{~min} v s 40.9 \pm 39.8 \mathrm{~min}, p<0.1)$. Stage 2 , REM latency and REM density did not change significantly. This analysis is very limited by the number of patients and the impossibility to take gender and response into account. At least a strong REM-promoting effect of tianeptine can be ruled out. These findings are in line with those of the acute effect in rats (Mocaer et al, 1988).

The gender differences in the sleep-EEG changes in the course of treatment described here point to a very basic rather than only a quantitative biological gender difference in the action of antidepressants and seem not a result of pharmacokinetic reasons alone. Here we presented a gender difference in the change of non-REM sleep spectral parameters in the course of treatment. The change in the sigma frequency in male subjects occurred regardless of the type of medication. It is important to note that two principally different types of spindles exist, those with a frequency of about $11-13 \mathrm{~Hz}$ and those with a frequency of about $14-16 \mathrm{~Hz}$ (Aeschbach et al, 1994; Tagaya et al, 2000; Landolt et al, 1996). Gender differences in the EEG spectrum of non-REM sleep exist in young healthy subjects (Dijk et al, 1989; Antonijevic et al, 1999a) and in patients with depression (Antonijevic et al, 2000b). Interestingly, the relation of the power of EEG activity of the higher sigma frequency range $(14-16 \mathrm{~Hz})$ to that of the delta frequency range $(0.5-4.5 \mathrm{~Hz})$ seems to be increased in male depressed subjects compared to healthy males, whereas depressed women do not show a difference compared to female controls (Antonijevic et al, 2000a). This could possibly mean that an increase in the $14-16 \mathrm{~Hz}$ sleep-EEG activity is a state marker for depression in males only. In the study of 
the sleep EEG in clinical trials, it is therefore necessary for the interpretation of the data to take gender into account. In one study, however, a decrease in the spectral power from 12 to $20 \mathrm{~Hz}$, including the spindle frequencies, has been shown to be a marker of a stable remission from depression in a sample of unmedicated subjects including both males and females with a predominance of females (Kupfer et al, 1993). Furthermore, both tianeptine and amitriptyline lead to a reduction of sleep spindles after acute administration in rats; however in this study a differentiation in high- and low-frequency spindles has not been performed (Mocaer et al, 1988). This could point to the importance of this frequency range as a state marker for depression in general. Interestingly, the EEG power in this frequency range is increased by $\mathrm{CRH}$ administration in healthy subjects (Antonijevic et al, 1999b) and rats (Ehlers et al, 1986), supporting an involvement of this peptide in the sleep-EEG changes observed in the course of antidepressant treatment and further pointing to its importance in the pathophysiology of depression (Holsboer, 1999).

Earlier studies examining if specific sleep-EEG changes under psychopharmacological treatment are linked to clinical response failed to do so (Mendlewicz et al, 1991; Heiligenstein et al, 1994). These studies, however, did not take gender-differences into account. The reason for the gender-specific changes in the high-frequency spindles in the course of depression is not known, but it might be due to the influence of sex steroids as this frequency range is also mainly affected by the menstrual cycle (Driver et al, 1996) and by sex steroids like progesterone (Friess et al, 1997). As alterations in the concentration of sex steroids are observed during depression (Baischer et al, 1995; Toren et al, 1996), an interaction between endocrine chances and sleep-EEG changes in the course of depression seems likely. For SSRIs like paroxetine, it is suggested that their action depends on adaptive changes of 5-HT receptor function, especially a desensitization of pre- and postsynaptic 5$\mathrm{HT}_{1 \mathrm{~A}}$-receptors and postsynaptic $5-\mathrm{HT}_{2}$ - receptors (De Vry, 1995). These adaptive changes are widely affected by sex steroids (Halbreich and Lumley, 1993). All these receptors act stimulatory at HPA-axis activity; thus, the adaptive changes during antidepressant therapy dampen its overactivity (Kent et al, 1998). Further, estrogens have a stimulatory effect, while androgrens have a dampening effect on HPA-axis activity in several stress models in humans (Jezova et al, 1996) and rats (Gray and Bingaman, 1996). Therefore, changes in their concentration could be related to the influence of these hormones on HPA-axis activity.

Another important structure involved in HPA-axis regulation and the pathophysiology of depression (Holsboer and Barden, 1996) is the hippocampus. This structure reacts sensitively to stress conditions with morphological changes, which might lead consequently to cognitive disturbances (McEwen et al, 1997). In this model, corticosterone leads to a dendritic atrophy similar to chronic stress (Magarinos et al, 1999). These atrophic changes show a gender-specific pattern (Galea et al, 1997) and can be prevented by tianeptine but not by the SSRIs fluoxetine and fluvoxamine (McEwen et al, 1997). Similarly, a measure for the functional activity of the hippocampus, namely the propensity to induce long-term potentiation (LTP), can give further insight. LTP is related to not only cognitive function but also to emotionality-related learning paradigms as the model of fear conditioning, and shows a gender difference with a more pronounced LTP induction and enhanced fear conditioning in male rats (Maren et al, 1994). Accordingly, estrogens reduce both LTP induction and fear conditioning (Gupta et al, 2001). Further, both fear conditioning and LTP are increased by CRH (Blank et al, 2002). Neonatal isolation, which is a model of depression (Heim and Nemeroff, 2001), leads to an increase in LTP, which was more pronounced in male than in female rats (Bronzino et al, 1996). These observations suggest a dependency of LTP on the endocrine environment. Acute inescapable stress also leads to a reduction of LTP via a glucocorticoid-receptor-dependent mechanism in a similar way as the administration of the SSRI fluoxetine (Shakesby et al, 2002). The reduction of LTP by both could be blocked by tianeptine without a change in corticosterone concentration. This finding points to a direct effect of tianeptine at a functional property of the hippocampus, which seems to be independent of endocrine changes. As, however, LTP shows gender differences tianeptine also should have a gender-specific effect. It could well be that differences are not revealed in our study owing to the small number of patients and the general heterogeneity of depressive disorders.

As we saw, a pronounced difference not only in the sleepEEG findings but also in the psychopathological predictors of males compared to females and the partial divergence between changes in sleep-EEG parameters and psychopathological parameters reveals the complexity of the situation. This shows that the psychopathological classification, and also the classification based on 'hard' data similar to those derived from the sleep EEG, cannot be taken solely, but always has to respect other possible factors, as shown here for gender.

Another finding was the predictive value of the REM density at D7 for the treatment outcome, which was only true for the paroxetine group but not for the tianeptine group. Since we did not perform a polysomnography at baseline conditions prior to drug treatment, it remains undetermined if the REM density at D7 reflects more the baseline value or the action of the medication. However, a similar association between a high REM density at baseline and poor response was observed with therapeutic sleep deprivation (Clark et al, 2000). One important aspect of the REM density is that it is a marker of depression in drug-free subjects and independent of gender (Lauer et al, 1991). It is affected by SSRIs (Hendrickse et al, 1994; Armitage et al, 1995b) in depressed subjects, and by sleep deprivation in healthy controls (Murck et al, 1999) and depressed subjects (Murck and Steiger, 2001), but not by tianeptine in depressed subjects, as presented before. A study using REM latency under medication-free condition as a predictor for the response with fluoxetine failed to do so (Heiligenstein et al, 1994). On the other hand, initial response of slow-wave EEG activity (Kupfer et al, 1989) and REM suppression (Höchli et al, 1986) to clomipramine and REM suppression to amitriptyline (Kupfer et al, 1978; Gillin et al, 1978) seems to have a prognostic value for clinical outcome. Comparing the figures of REM density in our study at D7 under the two different drugs, we submit an initial REM 
density suppression by paroxetine, which is followed by an increase in REM density in the course of the treatment. This increase might accompany treatment response. Earlier studies showed that the REM-density was increased in women treated with fluoxetine even after the drug was discontinued compared to a pre-drug condition (Buysse et al, 1999b), whereas, in contrast, depressed patients treated nonpharmacologically show a decrease in REM density in the course of treatment (Thase et al, 1994; Buysse et al, 1999b). This points to a complex interaction of different structures involved in REM-sleep regulation. An example for such an interaction is that $5-\mathrm{HT}_{1 \mathrm{~A}}$ receptors, which undergo adaptive changes in the course of antidepressive treatment, mediate an increase in REM sleep if activated at the dorsal raphe nucleus (Bjorvatn $e t$ al, 1997), but decrease REM sleep if acting at pontine cholinergic nuclei (Sanford et al, 1994). This also shows that changes in the profile of the sleep EEG have to be interpreted with care.

Important limitations of the study exist. Firstly, it lacks the inclusion of baseline characteristics; therefore, the prediction of response by sleep-EEG variables was influenced by the medication. Further, we did not take the dose of the medications, which was allowed to be increased according to clinical response, or plasma levels into account. However, at least clinical response does not show a strong correlation with the dose, if it is beyond a certain level (Bollini et al, 1999). Additionally, because of the small number of subjects and the multiple comparisons, it might well be that more subtle changes than those described here could not be observed. Further, for the EEG parameters, we only used mean values of the total night. This might leave important effects of drugs unrevealed, as within one night the effects can be confined to specific time zones, possibly as a result of rapid adaptive changes (Murck et al, 2001). Lastly, it might well be that a characterization simply by using HAMD scores on the basis of an ICD-10 diagnosis of a depressive disorder includes a very heterogeneous group of patients, and a more syndrome-related differentiation might be more necessary to describe the effects of drugs more specifically (Murck, 2002).

In conclusion, we found no significant differences between tianeptine and paroxetine regarding efficacy, but a trend to a better efficacy of paroxetine in females. Paroxetine showed the known classical effects of SSRI on REM sleep, whereas tianeptine was devoid of REM effects. The effects of the treatments on spectral analysis parameters of the non-REM sleep EEG differed depending on gender, but were independent of the type of medication. The decline in higher frequency sigma in male responders was seen with both medications. Our findings of a differential change in the non-REM EEG activity with respect to gender but independent of medication point to a basic difference in the sleep regulating system in men compared to women. The attempt to correlate sleep-EEG parameters with psychopathological variables led to the finding that the presence of somatic complaints predicted response in females and nonresponse in males, and an increase in sigma power in females correlates with a decrease in this symptomatology. However, regardless of gender, REM density is of predictive value for the clinical outcome and parallels changes in clinical response with paroxetine.

\section{ACKNOWLEDGEMENTS}

The study was supported by I RIS, Courbevoie. We thank M Ising for useful comments on an earlier version of the manuscript.

\section{REFERENCES}

Aeschbach D, Dijk DJ, Trachsel L, Brunner DP, Borbely, AA (1994). Dynamics of slow-wave activity and spindle frequency activity in the human sleep EEG: effect of midazolam and zopiclone. Neuropsychopharmacology 11: 237-244.

Antonijevic IA, Murck H, Frieboes RM, Barthelmes J, Steiger A (2000a). Sexually dimorphic effects of GHRH on sleep-endocrine activity in patients with depression and normal controls - part I: the sleep EEG. Sleep Res Online 3: 5-13.

Antonijevic IA, Murck H, Frieboes RM, Holsboer F, Steiger A (1999a). On the gender differences in sleep-endocrine regulation in young normal humans. Neuroendocrinology 70: 280-287.

Antonijevic IA, Murck H, Frieboes RM, Schier T, Holsboer F, Steiger A (1999b). Hyporesponsiveness of the pituitary to CRH during slow wave sleep is not mimicked by systemic GHRH. Neuroendocrinology 69: 88-96.

Antonijevic IA, Murck H, Frieboes RM, Steiger A (2000b). Sexually dimorphic effects of GHRH on sleep-endocrine activity in patients with depression and normal controls - part II: hormone secretion. Sleep Res Online 3: 15-21.

Armitage R, Hudson A, Trivedi M, Rush, AJ (1995a). Sex differences in the distribution of EEG frequencies during sleep: unipolar depressed outpatients. J Affect Disord 34: 121-129.

Armitage R, Trivedi M, Rush AJ (1995b). Fluoxetine and oculomotor activity during sleep in depressed patients. Neuropsychopharmacology 12: 159-165.

Baischer W, Koinig G, Hartmann B, Huber J, Langer G (1995). Hypothalamic-pituitary-gonadal axis in depressed premenopausal women: elevated blood testosterone concentrations compared to normal controls. Psychoneuroendocrinology 20: 553-559.

Bjorvatn B, Fagerland S, Eid T, Ursin R (1997). Sleep/waking effects of a selective 5-HT1A receptor agonist given systemically as well as perfused in the dorsal raphe nucleus in rats. Brain Res 770: 81-88.

Blank T, Nijholt I, Eckart K, Spiess J (2002). Priming of long-term potentiation in mouse hippocampus by corticotropin-releasing factor and acute stress: implications for hippocampus-dependent learning. J Neurosci 22: 3788-3794.

Bollini P, Pampallona S, Tibaldi G, Kupelnick B, Munizza C (1999). Effectiveness of antidepressants Meta-analysis of dose-effect relationships in randomised clinical trials. Br J Psychiatry 174: 297-303.

Bronzino JD, Kehoe P, Austin-LaFrance RJ, Rushmore RJ, Kurdian J (1996). Neonatal isolation alters LTP in freely moving juvenile rats: sex differences. Brain Res Bull 41: 175-183.

Budziszewska B, Jaworska-Feil L, Kajta M, Lason W (2000). Antidepressant drugs inhibit glucocorticoid receptor-mediated gene transcription - a possible mechanism. Br J Pharmacol 130: 1385-1393.

Buysse DJ, Kupfer DJ, Cherry C, Stapf D, Frank E (1999a). Effects of prior fluoxetine treatment on EEG sleep in women with recurrent depression. Neuropsychopharmacology 21: 258-267.

Buysse DJ, Kupfer DJ, Cherry C, Stapf D, Frank E (1999b). Effects of prior fluoxetine treatment on EEG sleep in women with recurrent depression. Neuropsychopharmacology 21: 258-267.

Clark C, Dupont R, Golshan S, Gillin JC, Rapaport MH, Kelsoe JR (2000). Preliminary evidence of an association between increased REM density and poor antidepressant response to partial sleep deprivation. J Affect Disord 59: 77-83. 
Connor TJ, Kelliher P, Shen Y, Harkin A, Kelly JP, Leonard BE (2000). Effect of subchronic antidepressant treatments on behavioral, neurochemical, and endocrine changes in the forced-swim test. Pharmacol Biochem Behav 65: 591-597.

De Vry J (1995). 5-HT1A receptor agonists: recent developments and controversial issues. Psychopharmacology 121: 1-26.

Delbende C, Tranchand BD, Tarozzo G, Grino M, Oliver C, Mocaer $\mathrm{E}$ et al (1994). Effect of chronic treatment with the antidepressant tianeptine on the hypothalamo-pituitary-adrenal axis. Eur $J$ Pharmacol 251: 245-251.

Dijk DJ, Beersma DG, Bloem GM (1989). Sex differences in the sleep EEG of young adults: visual scoring and spectral analysis. Sleep 12: 500-507.

Driver HS, Dijk DJ, Werth E, Biedermann K, Borbely AA (1996). Sleep and the sleep electroencephalogram across the menstrual cycle in young healthy women. J Clin Endocrinol Metab 81: 728735.

Ehlers CL, Reed TK, Henriksen SJ (1986). Effects of corticotropinreleasing factor and growth hormone-releasing factor on sleep and activity in rats. Neuroendocrinology 42: 467-474.

Friess E, Tagaya H, Trachsel L, Holsboer F, Rupprecht R (1997). Progesterone-induced changes in sleep in male subjects. $A m \mathrm{~J}$ Physiol Endocrinol Metals 272: E885-E891.

Galea LA, McEwen BS, Tanapat P, Deak T, Spencer RL, Dhabhar FS (1997). Sex differences in dendritic atrophy of CA3 pyramidal neurons in response to chronic restraint stress. Neuroscience 81: 689-697.

Gillin JC, Wyatt RJ, Fram D, Snyder F (1978). The relationship between changes in REM sleep and clinical improvement in depressed patients treated with amitriptyline. Psychopharmacology (Berl) 59: 267-272.

Gray TS, Bingaman EW (1996). The amygdala: corticotropinreleasing factor, steroids, and stress. Crit Rev Neurobiol 10: 155168.

Gupta RR, Sen S, Diepenhorst LL, Rudick CN, Maren S (2001). Estrogen modulates sexually dimorphic contextual fear conditioning and hippocampal long-term potentiation (LTP) in rats(1). Brain Res 888: 356-365.

Halbreich U, Lumley LA (1993). The multiple interactional biological processes that might lead to depression and gender differences in its appearance. J Affect Disord 29: 159-173.

Heiligenstein JH, Faries DE, Rush AJ, Andersen JS, Pande AC, Roffwarg HP et al (1994). Latency to rapid eye movement sleep as a predictor of treatment response to fluoxetine and placebo in nonpsychotic depressed outpatients. Psychiatry Res 52: 327-339.

Heim C, Nemeroff CB (2001). The role of childhood trauma in the neurobiology of mood and anxiety disorders: preclinical and clinical studies. Biol Psychiatry 49: 1023-1039.

Hendrickse WA, Roffwarg HP, Grannemann BD, Orsulak PJ, Armitage R, Cain JW et al (1994). The effects of fluoxetine on the polysomnogram of depressed outpatients: a pilot study. Neuropsychopharmacology 10: 85-91.

Höchli D, Riemann D, Zulley J, Berger M (1986). Initial REM sleep suppression by clomipramine: a prognostic tool for treatment response in patients with a major depressive disorder. Biol Psychiatry 21: 1217-1220.

Holsboer F (1999). The rationale for corticotropin-releasing hormone receptor (CRH-R) antagonists to treat depression and anxiety. J Psychiatr Res 33: 181-214.

Holsboer F, Barden N (1996). Antidepressants and hypothalamicpituitary-adrenocortical regulation. Endocr Rev 17: 187-205.

Jezova D, Jurankova E, Mosnarova A, Kriska M, Skultetyova I (1996). Neuroendocrine response during stress with relation to gender differences. Acta Neurobiol Exp 56: 779-785.

Kelly JP, Leonard BE (1994). The effect of tianeptine and sertraline in three animal models of depression. Neuropharmacology 33: 1011-1016.
Kent JM, Coplan JD, Gorman JM (1998). Clinical utility of the selective serotonin reuptake inhibitors in the spectrum of anxiety. Biol Psychiatry 44: 812-824.

Kornstein SG (1997). Gender differences in depression: implications for treatment. J Clin Psychiatry 58(Suppl 15): 12-18.

Kornstein SG, Schatzberg AF, Thase ME, Yonkers KA, McCullough JP, Keitner GI et al (2000). Gender differences in treatment response to sertraline versus imipramine in chronic depression. Am J Psychiatry 157: 1445-1452.

Kupfer DJ, Ehlers CL, Frank E, Grochocinski VJ, McEachran AB, Buhari A (1993). Electroencephalographic sleep studies in depressed patients during long-term recovery. Psychiatry Res 49: $121-138$

Kupfer DJ, Ehlers CL, Pollock BG, Nathan RS, Perel JM (1989). Clomipramine and EEG sleep in depression. Psychiatry Res 30: 165-180.

Kupfer DJ, Spiker DG, Coble P, McPartland RJ (1978). Amitriptyline and EEG sleep in depressed patients: I. Drug effect. Sleep 1: 149-159.

Kupfer DJ, Spiker DG, Coble PA, Neil JF, Ulrich R, Shaw DH (1981). Sleep and treatment prediction in endogenous depression. Am J Psychiatry 138: 429-434.

Landolt HP, Dijk DJ, Achermann P, Borbely AA (1996). Effect of age on the sleep EEG: slow-wave activity and spindle frequency activity in young and middle-aged men. Brain Res 738: 205-212.

Lauer C, Riemann D, Wiegand M, Berger M (1991). From early to late adulthood. Changes in EEG sleep of depressed patients and healthy volunteers. Biol Psychiatry 29: 979-993.

Magarinos AM, Deslandes A, McEwen BS (1999). Effects of antidepressants and benzodiazepine treatments on the dendritic structure of CA3 pyramidal neurons after chronic stress. Eur J Pharmacol 371: 113-122.

Maren S, De Oca B, Fanselow MS (1994). Sex differences in hippocampal long-term potentiation (LTP) and Pavlovian fear conditioning in rats: positive correlation between LTP and contextual learning. Brain Res 661: 25-34.

McEwen BS, Conrad CD, Kuroda Y, Frankfurt M, Magarinos AM, McKittrick C (1997). Prevention of stress-induced morphological and cognitive consequences. Eur Neuropsychopharmacol 7(Suppl 3): S323-S328.

Mendlewicz J, Kempenaers C, de Maer-lelaer V (1991). Sleep EEG and amitryptiline treatment in depressed inpatients. Biol Psychiatry 30: 691-702.

Mocaer E, Rettori MC, Kamoun A (1988). Pharmacological antidepressive effects and tianeptine-induced 5-HT uptake increase. Clin Neuropharmacol 11(Suppl 2): S32-S42.

Mundo E, Bareggi SR, Pirola R, Bellodi L (1999). Effect of acute intravenous clomipramine and antiobsessional response to proserotonergic drugs: is gender a predictive variable? Biol Psychiatry 45: 290-294.

Murck H (2002). Atypical depression and related disorders - neurobiological basis for their treatment with St. John's wort. Wien Med Wochenschr, 152: 398-403.

Murck H, Antonijevic IA, Schier T, Frieboes RM, Barthelmes J, Steiger A (1999). Aging does not affect the sleep endocrine response to total sleep deprivation in humans. Neurobiol Aging 20: $665-668$.

Murck H, Frieboes RM, Antonijevic IA, Steiger A (2001). Distinct temporal pattern of the effects of the combined serotoninreuptake inhibitor and 5-HT1A agonist EMD 68843 on the sleep EEG in healthy men. Psychopharmacology (Berl) 155: 187-192.

Murck H, Steiger A (2001). Sleep-endocrine changes after sleep deprivation in depression - focus on the renin-angioteninaldosterone system. Biol Psychiatry 49: 103S.

Nickel T, Sonntag A, Schill J, Zobel AW, Ackl N, Brunnauer A et al. Clinical and neurobiological effects of tianeptine and paroxetine in major depression. J Clin Psychopharmacol, in press. 
Nofzinger EA, Reynolds $3 \mathrm{CF}$, Thase ME, Frank E, Jennings JR, Fasiczka AL et al (1995). REM sleep enhancement by bupropion in depressed men. Am J Psychiatry 152: 274-276.

Rechtschaffen A, Kales A (1968). A Manual of Standardized Terminology, Techniques and Scoring System for Sleep Stages of Human Subjects. US Department of Health, Education \&Welfare, Neurological Information Network, Bethesda, MD.

Reynolds III CF, Kupfer DJ, Thase ME, Frank E, Jarrett DB, Coble PA et al (1990). Sleep, gender, and depression: an analysis of gender effects on the electroencephalographic sleep of 302 depressed outpatients. Biol Psychiatry 28: 673-684.

Sanford LD, Ross RJ, Seggos AE, Morrison AR, Ball WA, Mann GL (1994). Central administration of two 5-HT receptor agonists: effect on REM sleep initiation and PGO waves. Pharmacol Biochem Behav 49: 93-100.

Shakesby AC, Anwyl R, Rowan MJ (2002). Overcoming the effects of stress on synaptic plasticity in the intact hippocampus: rapid actions of serotonergic and antidepressant agents. J Neurosci 22: 3638-3644
Sharpley AL, Cowen PJ (1995). Effect of pharmacologic treatments on the sleep of depressed patients. Biol Psychiatry 37: 85-98.

Steiger A, Benkert O, Wöhrmann S, Steinseifer D, Holsboer F (1989). Effects of trimipramine on sleep EEG, penile tumescence and nocturnal hormonal secretion. A long-term study in 3 normal controls. Neuropsychobiology 21: 71-75.

Tagaya H, Trachsel L, Murck H, Antonijevic I, Steiger A, Holsboer $\mathrm{F}$ et al (2000). Temporal EEG dynamics of non-REM sleep episodes in humans. Brain Res 861: 233-240.

Thase ME, Reynolds III CF, Frank E, Jennings JR, Nofzinger E, Fasiczka AL et al (1994). Polysomnographic studies of unmedicated depressed men before and after cognitive behavioral therapy. Am J Psychiatry 151: 1615-1622.

Toren P, Dor J, Rehavi M, Weizman A (1996). Hypothalamicpituitary-ovarian axis and mood. Biol Psychiatry 40: 1051-1055.

Vogel G, Cohen J, Mullis D, Kensler T, Kaplita S (1998). Nefazodone and REM sleep - how do antidepressant drugs decrease REM sleep. Sleep 21: 70-77. 